\title{
Use Of The Best Practices Technique In Business And Ways To Maximize Its Usefulness
}

Michael Anikeeff, (E-mail: mikea@jhu.edu), Johns Hopkins University Ven Sriram, (E-mail: vsriram@ubmail.ubalt.edu), University of Baltimore

\begin{abstract}
The approach of identifying and learning from the best practices employed in an industry is popular in academic and professional business training. The concept of following the leader (similar to benchmarking) is a trusted tactic, if not a strategy, used in many industries. However, if the correct research method is not used to identify these practices, the outcomes can be ineffective as a result of using inappropriate techniques, or inefficient as result of using techniques that promise success yet result in failure. This paper discusses how best practices may sometimes be erroneously identified and provides guidance on how to avoid the error. The research is based on an experience with the hospice sector of the health care industry.
\end{abstract}

\section{Introduction}

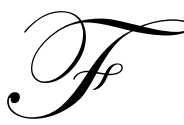

or-profit and non-profit hospice organizations are integral parts of the health care system. The services they provide are critical to individuals and their friends and families. The industry is currently facing difficulties due to a decrease in the average length of stay (LOS) of residents. The economic structure is one that has high fixed costs at the beginning of the stay and at the end of the stay. The revenue is a constant daily rate.

\section{Background}

The first Hospice in the US began in Connecticut in 1974. Hospice provides palliative care rather than curative care. Hospice services include a variety of services: supportive medical, social, emotional, and spiritual to the terminally ill as well as support for the patient's family. The care is offered primarily in the patient's home. Hospice care involves an interdisciplinary team of physicians, nurses, medical social workers, therapists, counselors, and volunteers. The team develops an individualized plan of care for each patient and family.

All sectors of the industry have grown over the last ten years; growth has been particularly strong in the forprofit sector and among large hospice programs. At the same time, hospice industry reports growing pressure from costs associated with shorter patient stays and changes in the practice of palliative care.

The number of Medicare-certified hospice providers grew by 82 percent from 1,208 (35 percent of hospices) in 1992 to 2,196 (80 per cent of hospices) in 1999 (GAO, HEHS, 1999). The total number of Medicare hospice providers peaked in 1998-1999. In this period, the 195 hospice program closures exceeded the 149 new program entrants. A disproportionate number of the hospice closures were among those based in home healthcare agencies (HHA). Although, HHA represented about a third of the hospices, they accounted for 43 percent of those that closed over the 2-year period.

The number of for-profit providers increased four fold and the number of large providers (over 500 Medicare patients) tripled over the period. Rural providers grew by 116 percent and urban providers by 64 percent. 
In spite of this growth the majority of providers are small (under 100 Medicare patients per year), organized as notfor-profits, and located in urban areas.

Cost Issues: There are concerns about costs among providers. Most significantly, declines in the average enrollment period have resulted in fewer days over which providers can spread the fixed costs associated with a patient's stay in a hospice. In addition, providers report that changes in the practice of palliative care have made the use of higher cost services more common. Hospice representatives say that the hours of nursing, social work, and administrative time the typical patient requires are about twice as high during the first and last weeks of a patient's care as they are during the intervening weeks. Therefore, the per diem payment system used by Medicare is less effective. As the enrollment periods decline, the hospices have fewer days over which they can spread the higher costs associated with the start and end of the patient's stay. More patients enter hospice later in the course of their terminal illness, and they enter at higher levels of impairment and in need of more intensive treatment. In addition, the mix of patients by diagnosis may have increased the average service needs for the overall hospice population.

Physicians and patients are asking for a broader array of palliative services. Expensive treatments such as chemotherapy traditionally used in curative settings, are increasingly used in hospices to manage pain and other symptoms. In addition, there are new treatments - administration of narcotic pain medication that offers better treatment at higher expense.

Hospice industry representatives reported being able to enroll most patients who were referred. With the exception of patients lacking sufficient informal friend or family caregiver support, the potential cost of care and payment rates was not generally cited as factors limiting the admission of eligible patients. The factors that affect the decisions about whether and when to use hospices depend on physician preferences and referral practices, individual patient choice and circumstances, and public and professional awareness of the benefit.

\section{Research Questions}

There is a trend toward greater use of hospice care and this has become prevalent in the 1990's. Patients with all types of terminal illnesses are using the services in greater numbers every year. Although the trend toward greater use is welcomed, patient advocates and the industry are concerned about the trend toward using fewer days of hospice care. Since many factors affect the use of hospice care, the potential demand is difficult to measure. The literature suggests multiple factors influence the use of hospice care: physician preferences and referral practices, patient awareness and preferences, and general awareness among the public and professional communities. In this study, we want to determine if there is a relationship between the factors deemed to influence the demand for hospice care and the average length of stay.

Specifically, our research questions (RQ) are:

$R Q$ 1. Is there a relationship between indicators of physician preferences and referral practices and hospice average length of stay?

Indicators include answers by hospice executives and managers to questions on: physicians reluctance to make timely referrals; regular visits to referring physicians; providing medical continuing education programs, seeing patients on request in physicians office; regular visits with referring physicians; marketing directly to physicians; use of medical directors to educate physicians; maintaining LOS statistics on physicians in the referral area; providing reports to physicians on the referrals and LOS of their patients in comparison with others, and providing a summary of car and services to physician after death or discharge.

$R Q$ 2: Is there a relationship between indicators of public and professional awareness and hospice average length of stay. 
Indicators include responses of hospice executives and managers to questions on: the use of advertising in local papers; use of newspaper articles advertising on radio; use of TV public service announcements; responding immediately to hospital referrals; meeting with hospital discharge planners, key hospital nursing staff and hospital social workers; use of informational meetings for the public on hospice issues around the end-of-life care; use of brochures or printed materials; providing palliative care consultation for pre-hospice; use of websites; targeting faithbased organizations; use of NHPCO's Guidelines or similar guidelines to educate physicians or other professionals.

$R Q$ 3: Is there a relationship between organizational external business environment and hospice average length of stay.

Indicators include responses to hospice executives and managers on: existence of competitors, changes in procedures; barriers to service; increased regulatory scrutiny.

$R Q 4:$ Is there a relationship between services provided and hospice average length of stay.

Indicators include responses to hospice executives and managers on: the availability of home health aides, the availability of after hour nursing services.

$R Q$ 5:Is there a relationship between organizational performance from one year to the next.

\section{Methodology}

The professional association, which represents the various organizations in the industry, asked researchers to work with the leading executives and managers to identify the means by which members could increase LOS. The approach followed was to study the best practices used by successful firms in the industry (i.e., those with long average length of stay). The practices of most interest dealt with marketing to the individual users of the service, their families and the gatekeepers in the health care system (doctors, hospital nurses or care specialists).

There is a problem with selecting only the practices of the best firms in that the relationship between best practices and performance may not be a function of the practices but of some other event. In order to maximize the benefit from the best practice approach, one must include poor performers and mediocre performers when testing for the application of practices. However, most best practice approaches used by business trade groups fail to consider the need for a control group in quasi-experimental research. Only this approach will reveal if it is the application of certain business strategies, or other factors entirely, which lead to success.

Think of the selection of a "best practice" as a quasi-experiment. The post-test is the identification of the best firm through some benchmark of performance. The treatment is the "practice"; in this study, marketing techniques. The pre-test is a benchmark score before the treatment was implemented. There are a number of problems with determining if the "best practice" was responsible for improved performance. The primary problem with this technique is a threat to external validity (Campbell and Russo, 1999, 84-104). External validity is the extent to which the effects can be generalized to other populations, and settings.

There are six problems with this type of one group design (no control group) according to the research methodology literature (Campbell and Russo 1999, 84-86):

1. History: specific events other than the experimental treatment occurring between the pre-test and post-test.

2. Maturation: this refers to a process rather than an event. In our case, the technological progress in improving the cure for diseases.

3. Testing: a change may occur as a result of the pre-test (benchmarking) even without the treatment. If your performance is measured, you pay attention to what is measured. 
4. Instrumentation: this refers to the shifting of the measuring of the instrument independent of the change in the phenomenon being measured. The "new broom" that changes the policy may reform the record keeping too.

5. Instability: change observed may be the result of the measures of small samples involved. In addition, instability can result from a large number of change-producing events of the type which taken individually were called history.

6. Regression: where a group has been selected because of its extreme performance in the pre-test and if the pre-test benchmark and post-test benchmark are imperfectly correlated it follows that on average the posttest will be less extreme than the pre-test.

In addition, by selecting only the best firms, the method has an additional problem. This specific situation is called confounding selection and treatment. The tactic gives favorable outcomes because it confounds selection and treatments so that the results show those receiving treatment are the more able. Treatments are given to the most promising, treatments like extensive marketing programs that are often adopted by those that need them least. The criterion of best firm selection operates in the same direction as the treatment. The test of best practice effectiveness is the comparison of all treated (best firms with marketing programs) with the mean of all untreated (mediocre or poor performers without extensive marketing programs). This will give a biased result.

\section{Data}

A sample of the hospices was generated from the membership of the National Hospice and Palliative Care Organization (NHPO). A letter was sent to a select group of managers and executives selected from the organization membership list at random. The executive of the organization mailed the letter explaining the importance of the study. The selected individuals were called at a time that was convenient and asked to respond to a series of questions. There were three sampling frames. The first was a simple random sample of the membership. The second was from a select list of hospices with a high LOS is 1999, and third list was selected from those with a low LOS. We received 113 usable responses out of 153 surveyed. There were 35 from the low LOS group, 39 from the high LOS group, and 39 from the sample of the total membership.

\section{Constructs and Measures}

The questionnaire was developed in concert with hospice executives and manages. The questionnaire was pilot tested for its clarity, readability, and to ensure that the items addressed issues of concern to decision-makers. Average length of stay (ALOS), median length of stay (MLOS), average daily census (ADC), which is the average number of patients in the facility, were self-reported data from 1999 and 2000. The primary dependent variable (ALOS in 1999) was identified by the NHPO as reported in annual performance reports. The interviewer verified the reported 1999 ALOS. The questions were of a nominal or interval scale. The interval questions were measured using a 5-point Likert-type scale anchored by "strongly disagree" (1) and "strongly agree" (5).

\section{Analytical Technique}

The questionnaire items with an interval scale, such as the perceived reluctance of physicians to make timely referrals, importance of radio advertising etc, were tested by comparing the means of the high ALOS hospice group with the low ALOS group using a t-test. The items with a nominal "yes" or "no" response - for example the availability home health aides or after hour nursing service - were tested using all of the respondents. We examined each question and the difference between the mean ALOS of the "yes" and "no" categories were evaluated using the t-test. In the final analysis, we tested the relationship between 1999 ALOS and 2000 ALOS, 1999 ADC and 2000 ADC using the Pearson's product-moment correlation coefficient. In all tests the significance level is .05. 


\section{Analysis}

The first set of tests compared the hospice organizations that had low ALOS with those that had a high ALOS in 1999. There was a statistically significant difference in only three instances. In short, for the most, part both high ALOS organizations and organizations with low ALOS agreed on the importance of the questionnaire items. In the three areas where there was a statistically significant difference, there was not an important decision-making difference. For example, in the scores which could range from " 1 " to " 5 ". The question about the importance of the lack of awareness about hospices, the low ALOS group received a mean score of 3.68 and a standard deviation of 1.01 and the high ALOS group a mean score of 2.97 and a standard deviation of 0.95 .

The industry problem, identified by further investigation, is a result of changes in the health care system and the overall business environment. The system changes resulted in changes in the patient mix of diseases in the facilities. In the past, most residents had cancer, which has a predictable average length of stay. Many of the current residents had problems such as heart disease, which have great variance in length of stay at the time of admission. Research showed that the success of the best firms resulted from the random and accidental selection of residents whose illnesses would require long LOS, not from the systematic application of any particular marketing strategies. In this study, the relationship between average daily census in 1999 and 2000 the correlation was $0.98, r$ squared 0.95 , a near perfect relationship. The organization's ADC from one year to the next was essentially the same. However, if we compare that relationship with the correlation between ALOS in 1999 and 2000 we see a difference. The correlation is 0.73 and the $r$ squared is 0.53 . This means that from one year to the next, a high or low ALOS in the first year only explains about 50 percent of the variation in the following year.

The results of the hospice study demonstrate some of the problems with the selection of the typical "best practice". The research technique actually used in this study differed from the selection of only the best firms. The successful firms were identified. The factors for marketing success were identified by the executives and managers and a survey form was developed and pre-tested. The survey was administered to over 100 firms including not only the best firms but also the mediocre and poor performers. The results were surprising and disappointing for the industry association that initiated the study since there was no significant difference in marketing techniques employed by organizations with long, average or short lengths of stay.

\section{Implications}

In sum, the relationship between best practices and performance may not be a function of the practices but of some other event. In order to maximize the benefit from the best practice approach, one must include poor performers and mediocre performers when testing for the application of practices. However, most best practice approaches used by business trade groups fail to consider the need for a more representative group or ideally a control group in what is quasi-experimental research. Only this approach will reveal if it is the application of certain business strategies, or other factors entirely, which lead to success.

This study compares the results of a best practice study with and without a more representative group though not a classic control group to illustrate the difference in approach. When there is a non-representative sample and no control group, erroneous conclusions can be drawn and ineffective strategies are recommended that can be very costly if implemented. We conclude that with care, one can avoid the pitfalls of the best practice approach and this technique can be employed effectively.

The support of the Global Business Studies program at the Merrick School of Business is gratefully acknowledged.

\section{References}

1. Basic Statistics About Hospice. (November 2001). Online fact sheet www.nahc.org.

2. Campbell, D. T. \& Russo, M. J. (1999). Social Experimentation. Thousand Oaks: Sage Publications 
3. General Accounting Office (GAO), (2000). Medicare: More Beneficiaries Use Hospice but for Fewer Days of Care.GAO/HEHS-00-182

4. Harwood, K. \& Shields, M. (1999). An Exploration of Hospice Referral: Barriers \& Enablers .The Robert Wood Johnson Foundation.

5. Institute of Medicine (IOM). (1997). Approaching Death: Improving Care at the End of Life. Washington, D.C.: National Academy Press.

6. National Hospice Organization. (1999). 1998 Length of Stay Fax Back Survey Final Report.

Notes 